\title{
SISTEM MONITORING TRAFIK PADA MIKROTIK BERBASIS APP MOBILE DENGAN NOTIFIKASI TELEGRAM
}

\author{
Muhammad Hanif ${ }^{1)}$, Made Kamisutara ${ }^{2}$ \\ 1), 2) Program Studi Teknik Informatika, Fakultas Ilmu Komputer, Universitas Narotama \\ JlArief Rachman Hakim No. 51, Surabaya \\ Email : muhammadhanief17@gmail.com ${ }^{1)}$, made.kamisutara@narotama.ac.id ${ }^{2)}$ \\ Corresponding author phone : +62 838-3012-2213
}

\begin{abstract}
Abstrak
Organisasi Perangkat Daerah (OPD) maupun Satuan Kerja Perangkat Daerah (SKPD) berkaitan erat dengan pelayanan publik yang berada di kota Surabaya, kompleksitas pelayanan publik yang di kelolah pada masing-masing OPD/SKPD sering kali menimbulkan beberapa kendala jaringan dan web server. untuk itu diperlukan pengelolahan infrastruktur, yang dapatmencegahterjadinya permasalahanjaringan maupun web server yang terjadi pada OPD/SKPD. Tujuan penelitian men ghasilkan sistem monitoring trafik jaringan dan webserver secara realtime dengan notifikasi telegram, untuk mencegah terjadinya kendala serta mempercepat proses penanganan kendala layanan publik pada OPD/SKPD. Penelitian ini menghasilkan system monitoring trafik jaringan dengan antar muka app mobile dan website. antarmuka app mobile dapat digunakan peng guna pada saat berada di lapangan, sedangkan antarmuka websitedapat digunakan pengguna pada saat berada di lingkungan kantor. Pengujian sistem monitoring dilakukan terhadap 10 OPD/SKPD yang berada di Surabaya serta 2 web server demo yang memberikan notifikasi berupa UP maupun Down secara real timemenggunakannotifikasi telegram. Serta notifikasijuga melalui website dengan menampilkan history jaringan maupun web server.
\end{abstract}

Kata kunci: Monitoring. Trafik Jaringan, Web Server, OPD/SKPD, Telegram

\begin{abstract}
Organisasi Perangkat Daerah (OPD) and Satuan Kerja Perangkat Daerah (SKPD) are related to public relation services in Surabaya, the complexity of public services managed to OPD / SKPD often creates several network and web server constraints. for that needed infrastructure management, which can prevent network and web server problems in OPD/SKPD. The research is to produce a real-time network traffic monitoring application and a webserver with telegramnotifications, to prevent obstacles and speed up the process of handling public service at OPD / SKPD. This research produces a network traffic monitoring system with a mobile app interface and a website. The mobile app interface can be used by users when in the field, while the website interface can be used by users when in an office environment. Monitoring system testing was carried out on 10 OPD/ SKPD in Surabaya with 2 demo web servers that provided real time UP and Down notifications using telegram notifications. As well as notifications also through the website by displaying network and web server history
\end{abstract}

Keywords : Monitoring, Traffic Network, Webserver, OPD/SKPD, Telegram

\section{PENDAHULUAN}

Kota Surabaya merupakan salah satu kota yang mendapat predikat smart city di Indonesia. Terdapat enam parameter smart city yang terdapat di Surabaya, yakni smart people, smart living, smart government, smart economy, smart mobility, dan smart environment [1]. Untuk menunjang smart city tentu infrastruktur yang ada disurabaya diperlukan pengelolahan teknologi informasi dan komunikasi yang saling terintegrasi antar organisasi perangkat daerah (OPD) maupun satuan kerja perangkat daerah (SKPD).

Pengelolahan teknologi informasi meliputi pengembangan sistem informasi, dan pemeliharaan jaringan komputer, pengelolaan produksi informasi dan publikasi, serta pengelolaan dan pengembangan komunikasi publik [2]. Namun infrastruktur jaringan yang digunakan oleh masing - masing instansi untuk pelayanan publik sering kali mengalami kendala. Kendala pada infrastruktur jaringan ini akan lebih baik jika dapat segera diketahui sehingga mengurangi kerugian yang dapat ditimbulkan, 
Untuk diperlukan sistem yang dapat melakukan monitoring jaringan. Yang dapat memberikan notifikasi secara real time yang history trafiknya tersimpan dan dapat diakses dimana saja. selain itu untuk mempercepat penyampaian informasi pada saat berada dilapangan digunakan pemanfaatan aplikasi social media telegram. Yang memiliki beberapa keunggulan diantaranya privasi, cloud storage, serta dukungan multi lebih baik diantara aplikasi social media lainnya [3]. Informasi yang diterima berupa notifikasi traffik jaringan dengan keadaan up maupun down. Sehingga pada saat koordinasi di lapangan dapat dilakukan dengan cepat dan sesuai dengan kondisi terkini pada OPD maupun SKPD.

Informasi yang disajikan berupa perangkat jaringan maupun server aplikasi yang mengalami kendala, baik perangkat jaringan mati akibat permasalahan listrik, error ataupun rusak. Begitu pula pada pemantauan server ketika ada indikasi kendala yang menyebabkan suatu halaman web tidak dapat digunakan sebagaimana mestinya. Sistem akan menampilkan informasi terkait server down sampai dengan server up. Semua kendala akan tercatat dan tersimpan sehingga dapat digunakan untuk audit maupun menentukan langkah preventif dalam penanganan kendala

\section{DASAR TEORI}

\subsection{Sistem Monitoring}

Manajemen jaringan adalah kemampuan untuk memonitor, mengontrol, dan merencanakan suatu jaringan komputer dan komponen sistem. Monitoring jaringan merupakan bagian dari manajemen jaringan. Hal yang paling mendasar dalam konsep manajemen jaringan adalah tentang adanya manajer atau perangkat yang memanajemen dan agen atau perangkat yang dikelolah [4].

\subsection{Mikrotik}

MikroTik RouterOS merupakan sistem operasi yang diperuntukkan sebagai network router. MikroTik router $\mathrm{OS}$ sendiri adalah sistem operasi dan perangkat lunak yang dapat digunakan untuk menjadikan komputer biasa menjadi router network yang handal, mencakup berbagai fitur yang dibuat untuk ip network dan jaringan wireless [5].

\subsection{NAT Firewall}

NAT merupakan singkatan dari Network Address Translation. NAT Firewall memungkinkan banyak perangkat di jaringan pribadi untuk berbagi gateway tunggal ke internet. Semua perangkat memiliki alamat IP publik yang sama - yaitu gateway - dan alamat IP pribadi yang unik. Gateway ditemukan pada router wifi dan beberapa layanan VPN. Misalnya, semua perangkat yang terhubung ke router wifi yang diaktifkan-NAT memiliki alamat IP pribadi yang berbeda, tetapi berbagi alamat IP publik router [6].

\subsection{Point To Point Tunneling Protocol (PTPTP)}

PPTP merupakan protokol jaringan yang dikembangkan oleh Microsoft dan Cisco yang memungkinkan pengamanan transfer data dari remote client ke server pribadi instansi dengan membuat sebuah VPN melalui TCP/IP. Teknologi jaringan yang terdapat pada PPTP adalah pengembangan dari remote access Point-to-Point Protocol yang dikeluarkan oleh Internet Engineering Task Force (IETF). PPTP membungkus paket PPP menjadi IP datagrams agar dapat ditransmisikan melalui internet atau jaringan public berbasis TCP/IP. PPTP juga dapat digunakan pada jaringan private LAN-toLAN [7].

\subsection{IP Address}

IP address adalah metode pengalamatan pada jaringan komputer dengan memberikan sederet angka pada komputer (host), router atau peralatan jaringan lainnya. IP address sebenarnya bukan diberikan kepada komputer (host) atau router, melainkan pada interface jaringan dari host / router tersebut [8].

\subsection{Routing}

Routing merupakan proses dimana sesuatu dibawa dari satu lokasi ke lokasi lainnya. Contoh riil sesuatu yang membutuhkan perutean adalah surat, panggilan telepon, perjalanan 
kereta api, dan lain sebagainya. Pada suatu jaringan router adalah perangkat yang digunakan untuk merutekan trafik jaringan [9].

\subsection{Domain Name System (DNS)}

Domain Name System (DNS) adalah sistem penerjemah yang mengubah nama host Internet (nama domain) ke seri yang unik dari nomor yang merupakan suatu Internet Protocol (IP) address untuk setiap nama domain yang spesifik. Mirip dengan nomor telepon, alamat IP yang diperlukan untuk rute paket dan berkoordinasi ke seluruh sistem Internet [10].

\subsection{System Development Life Cycle (SDLC)}

Software Development Life Cycle merupakan salah satu model pengembangan perangkat lunak waterfall, yang melakukan proses mengembangkan atau mengubah suatu sistem perangkat lunak dengan menggunakan model-model dan metodologi yang digunakan orang untuk mengembangkan sistem-sistem perangkat lunak sebelumnya, berdasarkan best practice atau caracara yang sudah teruji baik [11].

\section{METODOLOGI PENELITIAN}

Metodologi penelitian, yang digunakan untuk bangun sistem monitoring trafik jaringan pada penelitian ini. Menggunakan metode system development life cycle (SDLC). Metode SDLC dimulai dari tahap pengumpulan data pada perangkat daerah hingga berakhir pada tahap pengujian sistem monitoring trafik menggunakan black box testing

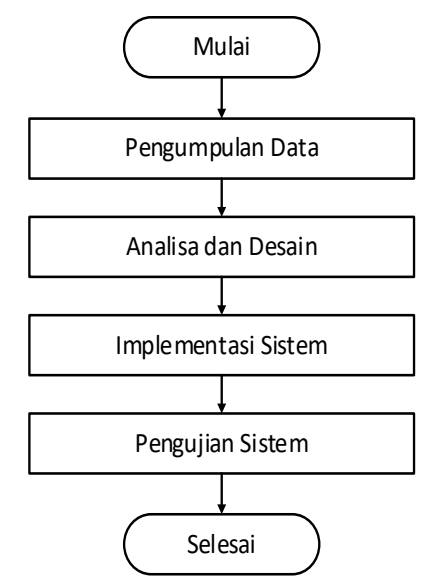

Gambar 1 Metodologi Penelitian

\subsection{Tahap Pengumpulan data}

Tahapan pengumpulan data terdiri dari studi literatur, pengumpulan data primer dan pengumpulan data sekunder. Studi literatur berguna untuk memperluas wawasan penulis yang berkaitan dengan monitoring database, jaringan dan server.

\subsection{Tahap Analisa dan Desain}

Tahapan analisa dan desain sistem monitoring database, jaringan dan server. Desain sistem pada monitoring jaringan ini menggunakan metode SDLC, data yang diperoleh dari tahapan pengumpulan data dari perangkat jaringan dan perangkat server akan dimasukan kedalam sistem monitoring dimana berguna untuk dilakukan pemantauan secara terstruktur.

\subsection{Tahap Implementasi Sistem}

Implementasi merupakan tahap pelaksanaan atau penerapan hasil desain atau rancangan yang sudah disusun sedemikia rupa, dalam bentuk perangkat lunak yang dapat digunakan secara keseluruhan. Adapun beberapa tahapan implementasi yang dilakukan pada penelitian ini :

1. Konfigurasi pada perangkat mikrotik

2. Implementasi Database 
3. Implementasi server aplikasi

4. Konfigurasi dengan aplikasi telegram sebagai notifikasi

\subsection{Tahap Pengujian Sistem}

Pengujian sistem monitoring perangkat lunak, yang dilakukan pada penelitian ini meliputi kesesuaian fungsi dari setiap menu ddan fitur yang akan di monitoring. Pengujian sistem monitoring ini, menggunakan pengujian black box testing.

\section{PENGUJIAN DAN PEMBAHASAN}

\subsection{Pengumpulan Data}

Pengumpulan data dilakukan pada salah satu perangkat daerah disurabaya, Adapun data yang digunakan pada penelitian yakni mekanisme penerimaan dan penginformasian gangguan yang dialami OPD/SKPD.

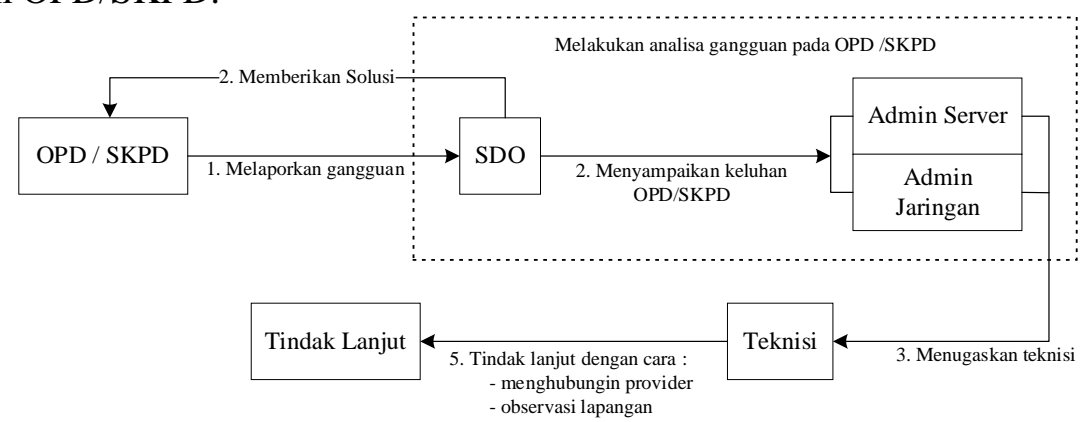

Gambar 2 Pelaporan ganguan oleh OPD/SKPD

Informasi perihal gangguan, tidak hanya diterima SDO berdasarkan informasi yang dikeluhkan oleh OPD/SKPD, tetapi juga melalui admin server atau admin jaringan yang kemudian di sampaikan ke OPD/SKPD terkait melalui SDO.

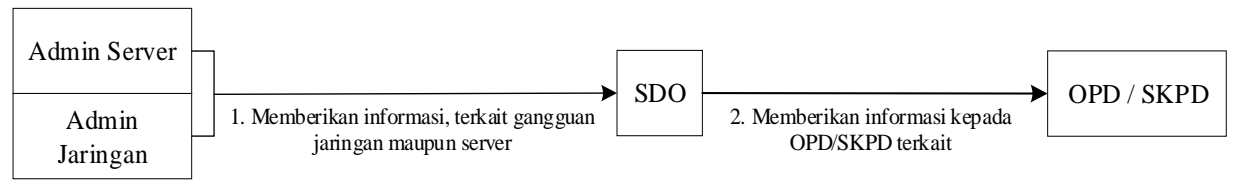

Gambar 3 Pemberian informasi ganguan kepada OPD/SKPD

Pemberian informasi gangguan kepada OPD/SKPD bertujuan untuk menginformasikan kepada OPD/SKPD lebih awal bahwa layanan yang melibatkan atau untuk masyarakat tidak dapat beroperasi untuk sementara waktu.

\subsection{Analisa dan Desain}

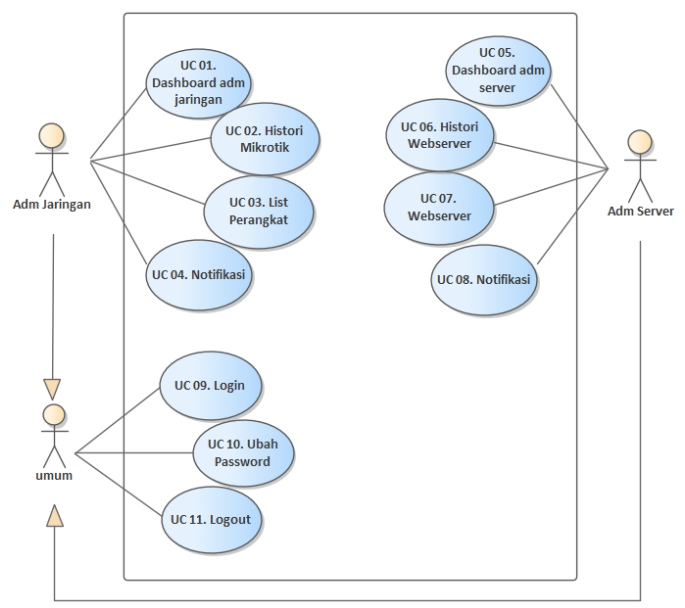

Gambar 4 Usecase Diagram 
Analisa dan desain sistem, pada penelitian ini, menggunakan diagam UML (Unified Modeling Language). Yang terbagi menjadi usecase diagram, activity diagram, dan user interface. Untuk membantu peneliti dalam membangun system monitoring trafik jaringan dan web server.

Usecase Diagram

Usecase diagram merupakan pengambaran fitur yang disajikan pada sistem monitoring trafik jaringan. Fitur yang disajikan berjumlah 8 fitur, dengan 2 pengguna yakni admin jaringan dan admin server.

\section{Activity Diagram}

Penggambaran activity diagram bertujuan untuk mendeskripsikan alur pada fitur yang telah dideskripsikan pada usecase diagram. Alur dan fitur yang disajikan sistem monitoring jaringan digambarkan pada gambar 5 dan 6 sebagai berikut :

1. Pengelolahan perangkat jaringan

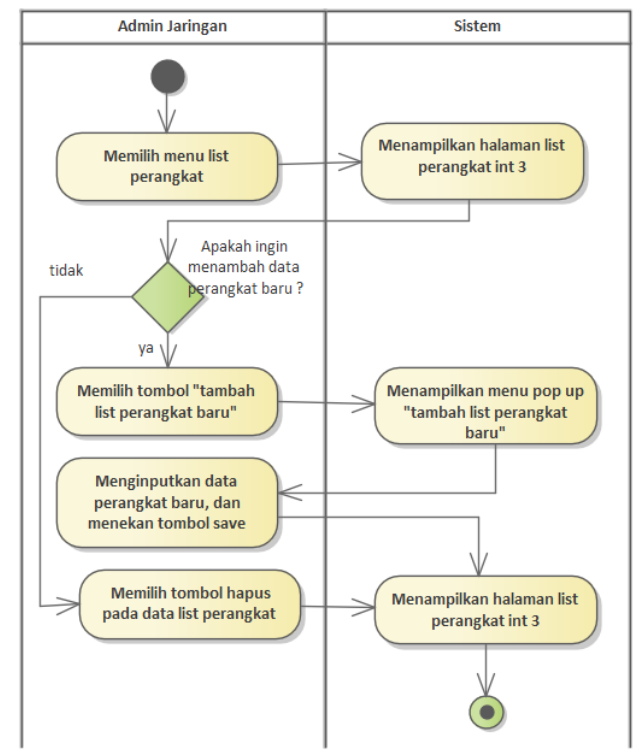

Gambar 5 Pengelolahan Perangkat Jaringan

Pengelolahan perangkat jaringan, berisi penambahan, pengurangan, serta perubahan data perangkat jaringan yang digunakan untuk melakukan monitoring jaringan pada OPD/SKPD yang berada di Surabaya. Yang nantinya data perangkat jaringan yang telah ditambahkan dapat dilakukan monitoring.

2. Pengelolahan data webserver

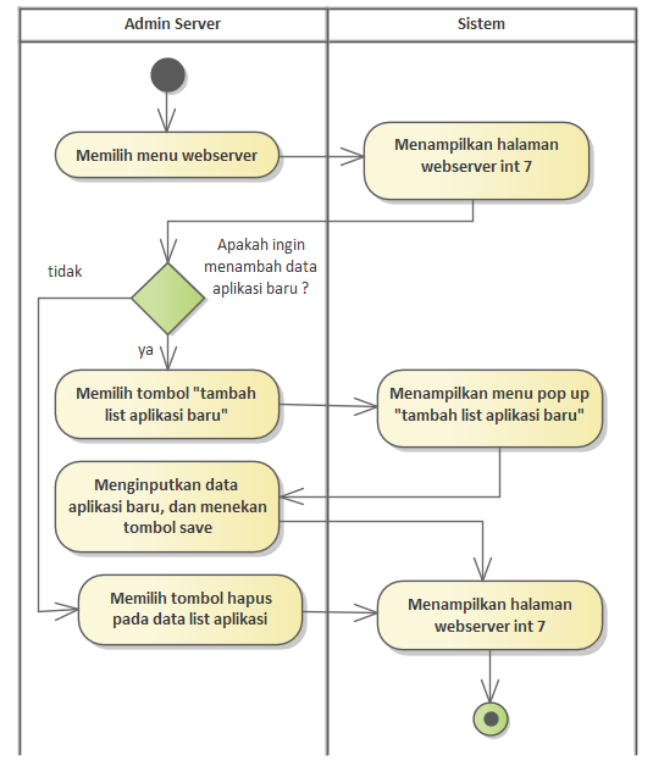

Gambar 6 Pengelolahan Data Webserver 
Pengelolahan data webserver, berisi penambahan, pengurangan, serta perubahan data webserver. yang digunakan untuk melakukan monitoring website atau aplikasi yang pelayanannya berada di OPD/SKPD. Yang nantinya data web server yang telah ditambahkan dapat dilakukan monitoring.

User Interface

Desain antar muka pada penelitian ini, menggambarkan monitoring jaringan dan webserver yang diterima oleh admin server dan admin jaringan. Menggunakan notifikasi telegram

1. Monitoring Jaringann Mikrotik

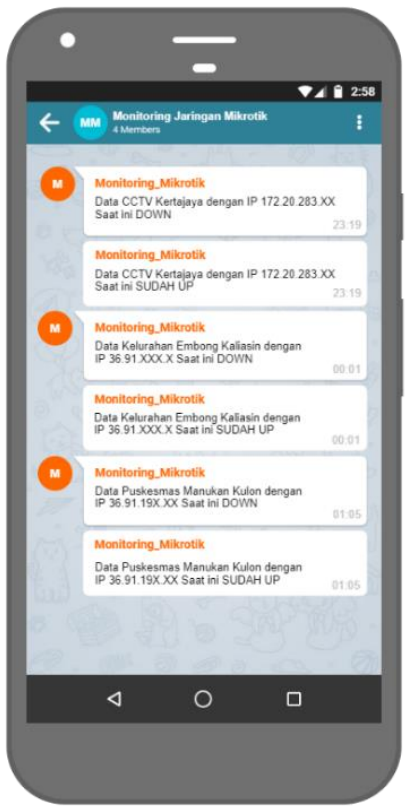

Gambar 7 Monitoring Jaringan Mikrotik

Notifikasi telegram, yang diterima oleh admin jaringan dan teknisi mengenai jaringan mikrotik berupa status $U p$ atau Down pada OPD/SKPD dengan range waktu 1 menit,

2. Monitoring Web Server

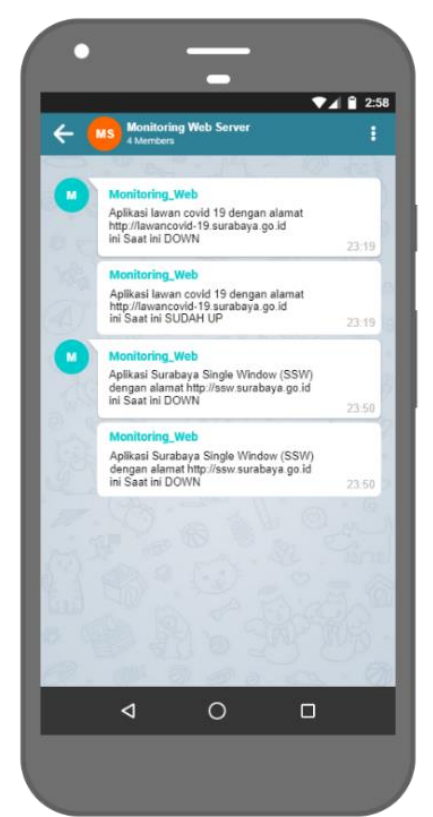

Gambar 8 Monitoring Web Server 
Notifikasi telegram yang diterima oleh admin web server dan teknisi mengenai web server yang berada di OPD/SKPD berupa status Up atau Down diterima oleh dengan range waktu 1 menit, Notifikasi telegram membantu admin jaringan, admin web server dan teknisi pada saat berada di lapangan untuk mempercepat penanganan gangguan yang dialami OPD/SKPD.

\subsection{Implementasi Sistem}

Implementasi sistem monitoring trafik pada mikrotik, menggunakan bahasa pemograman PHP, dan Codeigniter sebagai frameworknya. Pemilihan framework codeigniter dikarenakan mudah di konfigurasikan.

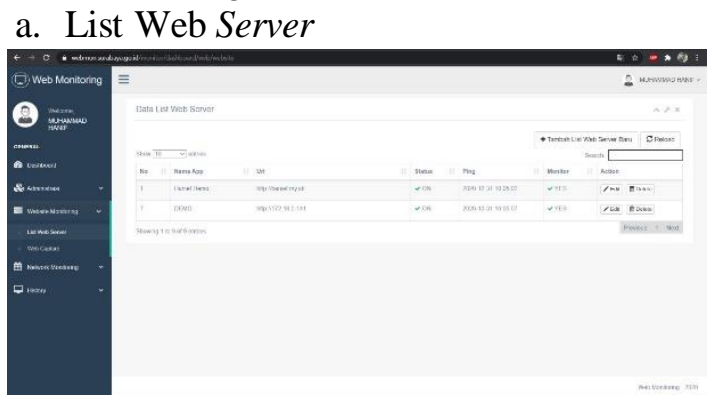

Gambar 9 List Web Server Antarmuka Website
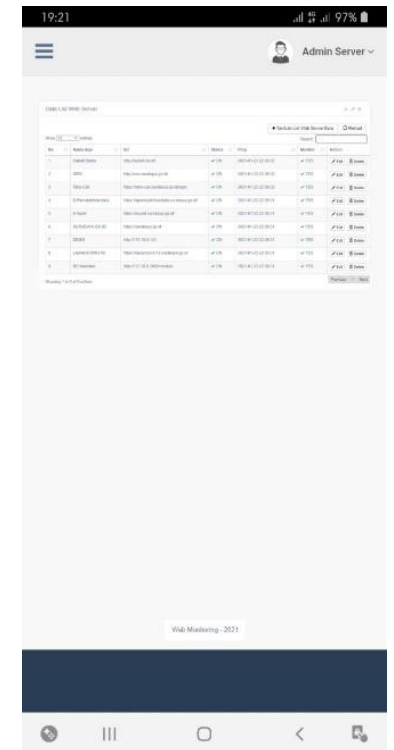

Gambar 10 List Web Server Antarmuka App Mobile

Halaman list web server, berisikan nama aplikasi, URL, status aplikasi, waktu terakhir aplikasi sedang down, monitor, dan aksi. Data web server dapat ditambahkan, diubah, maupun dihapus sesuai dengan kebutuhan perangkat daerah.

b. List Perangkat Mikrotik

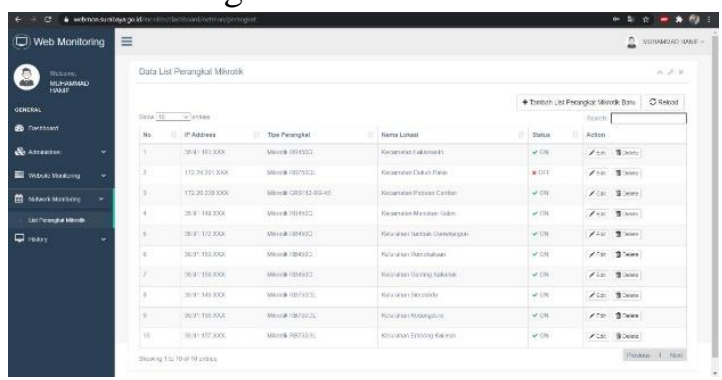

Gambar 11 List Perangkat Mikrotik

Antarmuka Website

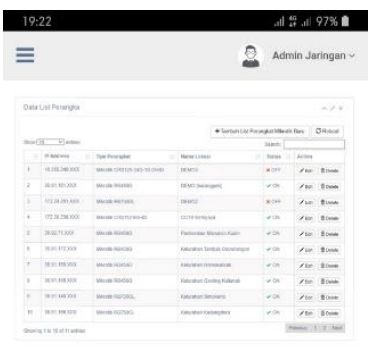

Gambar 12 List Perangkat Mikrotik Antarmuka App Mobile 
Halaman list perangkat mikrotik, berisikan alamat IP, tipe perangkat yang digunakan, nama lokasi perangkat, dan aksi. Data perangkat mikrotik dapat ditambahkan, diubah, maupun dihapus sesuai dengan kebutuhan perangkat daerah.

c. Data Log Perangkat

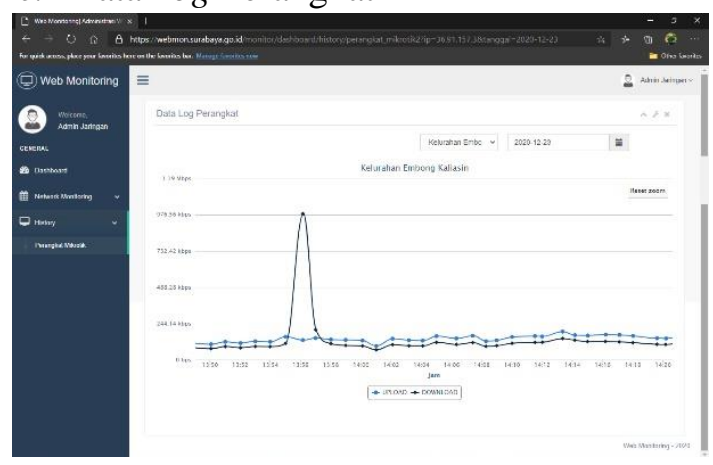

Gambar 13 Data Log Perangkat Antarmuka Website

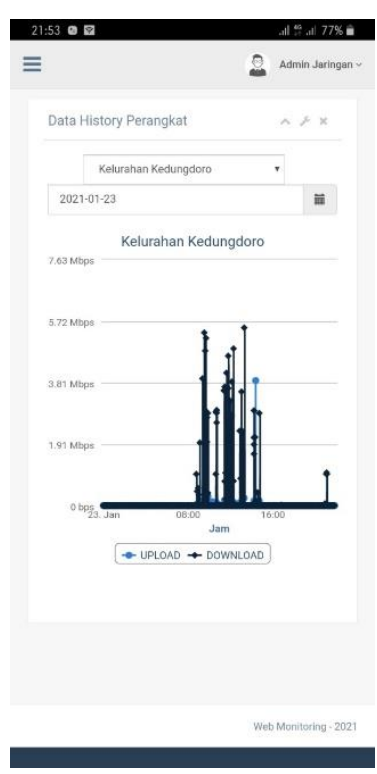

Gambar 14 Data Log Perangkat Antarmuka App Mobile

Halaman data log perangkat, merupakan informasi trafik jaringan pada OPD/SKPD yang telah ditambahkan pada halaman list perangkat mikrotik sebelumnya. Trafik penggunaan aplikasi tersebut, bersifat real time dan tersimpan setiap hari,

d. Data Log Web Server
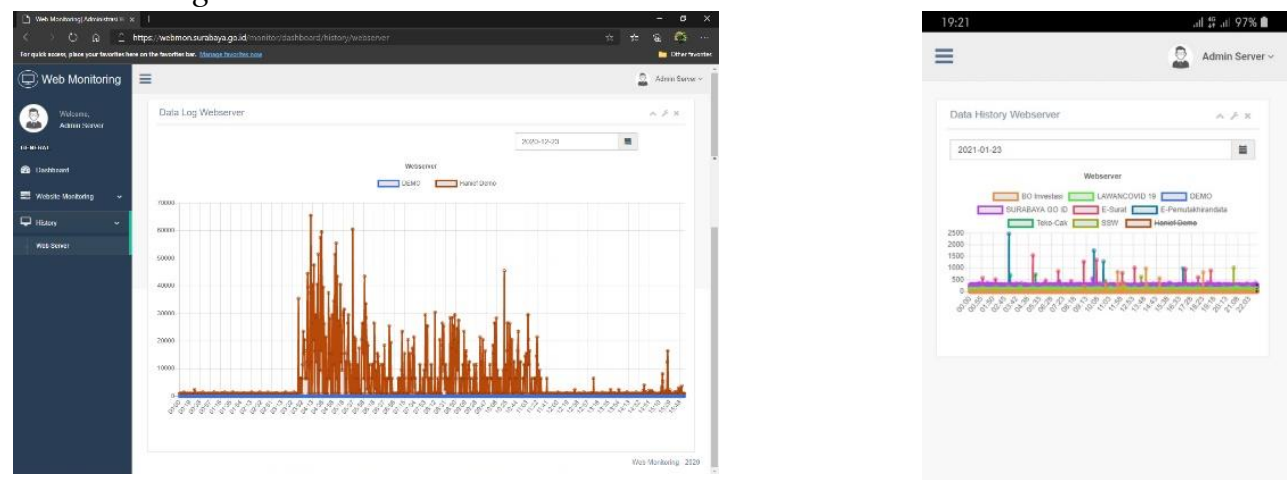

Gambar 15 Data Log Web Server Antarmuka Website

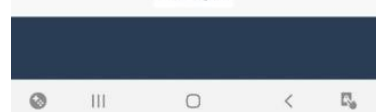

Gambar 16 Data Log Web Server Antarmuka App Mobile

Halaman $\log$ web server, merupakan informasi trafik penggunaan aplikasi yang sedang diakses pengguna pada OPD/SKPD. Trafik penggunaan aplikasi tersebut, bersifat real time dan tersimpan setiap hari.

\subsection{Pengujian Sistem}

Pengujian sistem monitoring trafik jaringan menggunakan dua parameter yakni pada development dan pengguna sistem. Pada parameter development, pengujian dilakukan 
menggunakan black box testing dengan penilaian keberhasilan berupa masing-masing tampilan menampilkan fungsi dan hasil yang diharapkan. Sedangkan pengujian sistem monitoring pada pengguna, di uji cobakan kepada 10 OPD/SKPD yang berada di Surabaya, dengan perangkat jaringan yang telah dinonaktifkan dan diaktifkan, serta digunakan terus menerus selama 24jam sedangkan pengujian sistem monitoring web server, diuji cobakan kepada 2 website, yang memiliki trafik jaringan cukup besar dan data yang tersedia pada website tersebut.

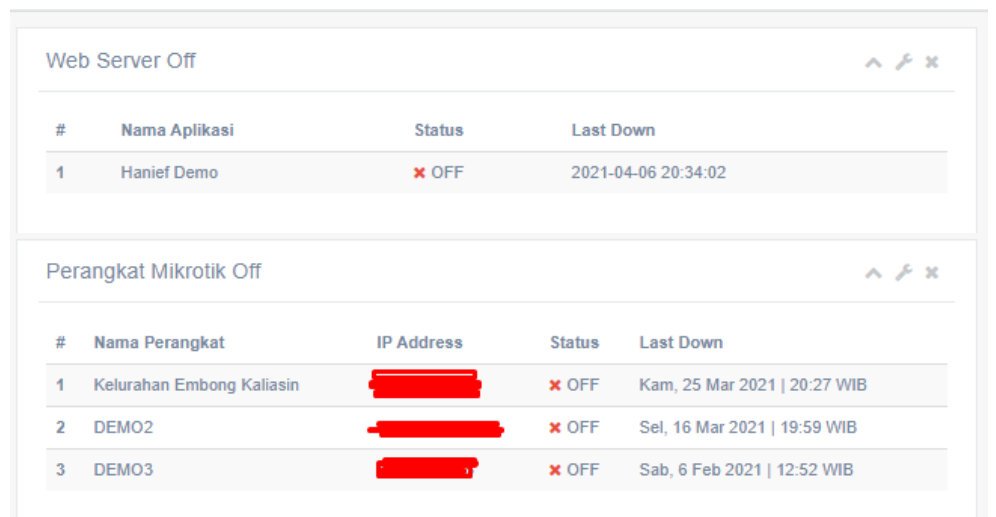

Gambar 17 Hasil Pengujian Perangkat Mikrotik Dan Webserver Yang Telah Dinonaktifkan

Pada gambar 17, merupakan hasil pengujian perangkat mikrotik dan webserver yang telah dinonaktifkan selama kurang lebih 15 menit. Halaman pengujian dilakukan pada halaman dashboard monitoring. Sedangkan pada gambar 18, merupakan hasil pengujian webserver yang telah diaktifkan kembali.

\section{KESIMPULAN}

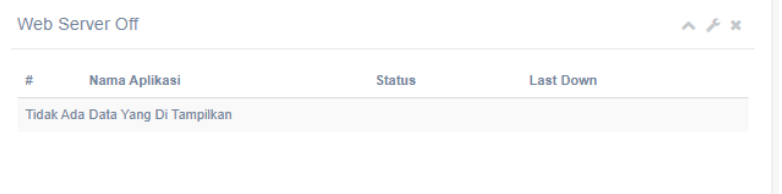

Sistem monitoring trafik pada mikrotik, membantu admin jaringan, admin webserver dalam pemantauan infrastruktur pada OPD/SKPD. Sehingga dalam proses penanganan gangguan dapat dengan mudah dilakukan. Notifikasi yang diterima oleh admin jaringan dan admin server, berupa notifikasi telegram dan notifikaso pada website berupa trafik jaringan dan web server.

\section{Daftar Pustaka}

[1] Adi Fida Rahman, "Smart City Surabaya Tak Sekadar e-Government," 2018. https://inet.detik.com/cyberlife/d-4305555/smart-city-surabaya-tak-sekadar-egovernment (accessed Jun. 19, 2020).

[2] W. M. La Hadisi, "Pengelolaan Teknologi Informasi Dalam Menciptakan Model Inovasi Pembelajaran ( E-Learning )," J. Al-Ta'dib, vol. 8, no. 1, pp. 117-140, 2015, doi: 10.1017/CBO9781107415324.004.

[3] J. Fahana, R. Umar, and F. Ridho, "Pemanfaatan Telegram sebagai Notifikasi Serangan untuk Jaringan Forensik," Query J. Inf. Syst., vol. 1, no. 2, pp. 6-14, 2017, [Online]. Available: http://jurnal.uinsu.ac.id/index.php/query/article/view/1036.

[4] R. Pradikta, A. Affandi, and E. Setijadi, "Rancang Bangun Aplikasi Monitoring Jaringan dengan Menggunakan Simple Network Management Protocol," J. Tek. ITS, vol. 2, no. 1, pp. A154-A159, 2013, [Online]. Available: http://www.ejurnal.its.ac.id/index.php/teknik/article/view/2265.

[5] Hendi, "Apa itu Mikrotik? - Cyberlink Networks," 2010. http://cyberlink.co.id/blog/apaitu-mikrotik/ (accessed Jun. 19, 2020).

[6] P. Bischoff, "What is a NAT firewall, How Does it Work and When Do You Need One?," 2019. https://www.comparitech.com/blog/vpn-privacy/nat-firewall/ (accessed Jun. 24, 
2020).

[7] A. B. U. Prihatin Oktivasari, "Analisa Virtual Private Network Menggunakan Open VPN Dan Point To Point Tunneling Protocol," J. Penelit. Komun. dan Opini Publik, vol. 2, pp. 185-202, 2016.

[8] S. Wardoyo, T. Ryadi, and R. Fahrizal, "Analisis Performa File Transport Protocol Pada Perbandingan Metode IPv4 Murni, IPv6 Murni dan Tunneling 6to4 Berbasis Router Mikrotik," J. Nas. Tek. Elektro, vol. 3, no. 2, p. 106, 2014, doi: 10.25077/jnte.v3n2.74.2014.

[9] Doro Edi, "Kajian Algoritma Routing Dalam Jaringan Komputer," J. Inform. UKM, vol. II, no. 3, pp. 47-55, 2006.

[10] A. Fujianto and I. Waspada, "Rancang Bangun Sistem Informasi Pengelolaan Dns Secara Terpusat ( Studi Kasus Cv . Surya Putra Perkasa ),” J. Infokam, vol. 1, pp. 9-10, 2016.

[11] Y. Firmansyah and U. Udi, "Penerapan Metode SDLC Waterfall Dalam Pembuatan Sistem Informasi Akademik Berbasis Web Studi Kasus Pondok Pesantren Al-Habib Sholeh Kabupaten Kubu Raya, Kalimantan Barat," J. Teknol. dan Manaj. Inform., vol. 4, no. 1, pp. 184-191, 2017, [Online]. Available: http://jurnal.uinsu.ac.id/index.php/query/article/view/1036. 